\title{
A Benchmarking Framework for Supply Chain Collaboration: A Data Envelopment Analysis (DEA) application
}

\author{
Assey Mbang Janvier-James (Corresponding author) \\ Glorious Sun School of Business and Management, Donghua University \\ PO box 200051, Shanghai, China \\ E-mail: asseyjanvier@hotmail.com
}

Evameye Didier

Centre de Formation professionnels Port-Gentil, Département de comptabilité,

BP 2237, Port-Gentil-Gabon

E-mail: evameye@yahoo.fr

Received: June 20, 2011 Accepted: July 21, $2011 \quad$ doi:10.5430/ijba.v2n3p19

\begin{abstract}
The objective of this study is to propose a method to measure the extent of collaboration and trust in a supply chain as important components of organizational behavior that contribute to the performance improvement of supply chain

The proposed model for collaboration can be classified on the basis of functional Supply Chain processes or Supply Chain relationship. A Data Envelopment Analysis (DEA) is introduced to evaluate the level of collaborative practices. The study uses quantitative data from a case study which shows the use of performance measurement-based DEA in a collaborative supply chain network. The finding of this study indicates that the corporate managers in non-performing Decision Making Units have a challenge that need to be improved. The major implication of these can be summed up as following: the underperforming RDs have measures of their own under-achievement enumerated. An examination of the input and output factors against the same factors of the best performers can provide managers with good strategies that should concrete the way forward. This provides an opportunity for individual RD improvements with the result that the Supply Chain improves. The limitation of the framework presented in this paper is that it is explanatory and based on work that has been investigated elsewhere. Some of the difficulties in the methodological problems of that work would be expected here: the choice of the Decision Making Units and the exact input and output factors would be important to the measurement outcome and to the effectiveness of Data envelopment analysis's ability to discriminate efficient from non-efficient Decision Making Units. Through this study, Supply chain managers will be able to assess the extent of their collaboration and seek improvement in their performance. This paper contributes to the existing literature by proposing a new performance measurement for assessing the extent of supply chain collaboration. This instrument can be used by any Supply Chain member to identify the level of collaboration and seek amelioration
\end{abstract}

Keywords: PM; SCN; Non-Parametric modeling, Collaboration, Corporate

\section{Introduction and Research Problematic}

Supply chain collaboration promotes the partnership of participants (members) along the supply chain to improve performance (Bowersox, D.J. 1990). The advantage of Supply Chain partnership include revenue augmentations, supply cost reductions, and functional flexibility to get along with high demand uncertainties (Fisher, M.L. ,1997).

Corporations like Sony, IBM, HP, Dell, and Wal-Mart that have cooperated with their partners, have captured the benefice of collaboration (Barratt, M. and Oliveira, A. 2001; Dell, M. and Fredman, C., 1999).

The acceptance of supply chain collaboration requires the development of knowledge sharing, and scientific means of accrediting values to account that show different levels of collaboration amongst members (Barratt, M. and Oliveira, A. 2001; Mentzer, J.M., Min, S. and Zacharia, Z.G. ,2000). Little work has been done to investigate such important and a complicated knowledge dimension of supply chain management (Tan, K.C., V.R. Kannan and R.B. Handfield. 1998) and this still represents a significant gap in the current literature. 
This paper depicts attempts to develop a method for the measurement of collaboration and trust as important factors of organizational behavior that plays an important role in the performance improvement of supply chain. This study is introduced with the research issues that are currently being examined in a Gabonese supply chain. These issues are being analyzed through the performance measurement conceptual framework, described by Performance Pyramid. Measurement is conducted by using a non-parametric research method based on linear programming.

The research problems of this study are: does the performance pyramid provide a performance measurement core that identifies weakness in collaborative relationships? Can the performance pyramid be applied to Supply Chain Networks in businesses to ameliorate competitive strategies? How can Data Envelopment Analysis be used in modeling Supply Chain effective collaboration for corporate performance?

The study is organized as follows. The next section reviews literature on Supply Chain collaboration performance measurement. The third section analyzes the Non-parametric algorithm. And the last section presents and discusses the findings. Finally, the paper provides concluding remarks and directions for future research.

\section{Literature Review}

\subsection{Measurements for Supply Chain Collaboration}

Both expert and academicians are progressively interested in SC collaboration (Corbett, C.J., Blackburn, J.D. and Van Wassenhove, L.N. 1999). Supply chain collaboration is generally defined as two or more corporate participants working together to create a competitive advantage through sharing crucial information, benefits, and making joint decisions (Simatupang, T.M. and Sridharan, R. 2002). The acceptance of SC collaboration would enhance along with the impacts of new information technology and globalization. Moreover, Supply Chain collaboration becomes a main principle in developing a flexible supply (Bowersox, D.J. ,1990, Narus, J.A. and Anderson, J.C. ,1996).

The wide acceptance of supply chain collaboration necessitates a tool to assess both internal and relative levels of collaborative practices (Barratt, M. and Oliveira, A. 2001)

Assessing collaborative practices internal levels helps the participants to determine the weakness of their levels and determine potential actions to alleviate them (Bowersox, D.J., Closs, D.J. and Keller, S.B., 2000) .The assessment also allows them to measure their levels of practice against the best-in-class entertainer (Simatupang, T.M. and Sridharan, R. 2004).

Furthermore, the participants acquire crucial feedback from assessing supply chain collaboration to determine the conclusive practice that mainly strengthen the supply chain effectiveness (Stewart, G. 1997).

Even if supply chain collaboration has acquired flourishing recognition, it is important to note that only few researches paid limited attention to assessing supply chain collaboration (Lambert, D.M. and Pohlen, T.L., 2001). Prior researches introduced measurement to benchmark the extent to which a corporate cooperates with its collaborators in a supply chain. The supply chain operations reference (SCOR) model has been introduced as the first framework for assessing and ameliorating supply chain performance (Stewart, G., 1997)

Bowersox, D.J., Closs, D.J. and Keller, S.B. (2000) created biased measurement of supply chain ability at both functional and decisive levels. By using system-wide revenues and costs, Ramdas, K. and Spekman, R.E. (2000) investigated collaborative practices between high performers among new-product SC and high performers among operational-product SC.

Efforts have been made to introduce the maturity model of collaboration as a tool to assess the degree of activity of supply chain collaboration from internal perspective to inter-organizational perspective. A framework containing four levels of supply chain optimization has been introduced by Poirier, C.C. (1999). This framework includes mainly sourcing and logistics and internal excellence. It also includes levels network construction and industry leadership which show the collaborative achievement between participating members. Additionally, Polese, W.T. (2002) developed a maturity model that shows how corporate improve in terms of functional competence. Collaborative effectiveness is the important factor in achieving external integration and cross-corporate collaboration.

Performance pyramid is also considered as the ultimate metric against which the performance of the corporate is measured. Performance pyramid is an outstanding conceptual model describing the businesses as a system composed of a number of aspects that contribute to the business performance (Judith Montgomery, 2008). The performance pyramid forms part of the PM conceptual framework

PM models such Balanced Scorecard and Performance Prism have been widely used for this reason (R.S. Kaplan, and D.P.Norton, 1993, 1992, Norreklit H., 2000). A further development of these performance measurement models is the performance prism. It provides a useful framework for developing Supply Chain measures (Sarah Shaw, David B. Grant, 
John Mangan, 2010). The metrics are mainly the scores for the performance dimensions of customer relationship, internal operations, and Supply Chain network. The Integral to performances besides these dimensions is the function of collaboration and relations in the SC.

Ivan Turok (2001), Marianne Kinnula (2004), and Maurice Atkinson (2005) demonstrated the creation of a qualitative collaborative model that can be adopted in attempts to achieve cost savings and reduce iteration of effort in collaborating corporate. Li, Z., Kumar, A. and Lim, Y.G. (2002) argue that this can be achieved with relational interdependences, plan building, information and process planning, and analysis using quantitative models. Chan, F.T.S. and Qi, H.J. (2003) proposed a new performance measurement method for supply chain management, using fuzzy set theory. This measurement method can be applied to improve logistic activities in the Supply Chain.

\subsection{Collaboration in the Integrated Supply Chain (SC) and Network}

\subsubsection{History of SC Collaboration}

Collaboration in the SC is a dynamic concept. In fact it is evolving over the last 20 years. Four major stages to achieve effective SC integration have been identified by Stevens G.C (1989) (Figure 1):

-Organization baseline (the organization is working with high-level operational specialization and consequently has a low ability to examine materials and information flow);

-Functional integrated corporate (the organization begins to concentrate on customer service);

- Internal integrated corporate (the organization besides the function of sales and distribution, integrate the production and purchasing activities).

- External integrated corporate (the organization includes customers and suppliers in the SCmanagement process).

It has been demonstrated that effective collaboration can provide competitive advantage in a buyer/supplier relation (R.Axelroad, 1990).

In the last 19 years, some trade association sponsors, created the "Efficient Consumer Response Movement (ECR)", with the aim of leading exceptional transformation in business practices. This was the first great initiative created to promote supply chain (SC) collaboration. Kurt Salmon Associates (1993) was among the first authors to give a clear definition to ECR: "Efficient Consumer Response is a joint industry and trade body. It can be defined as a responsive, consumer-driven system which allows distributors and suppliers to work together in order to reduce the overall cost and increase consumer satisfaction". ECR Europe (1997) defines the concept as "Working together to satisfy consumer demand, better, faster and at less cost”.

Whilst Efficient Consumer Response Movement brings many benefits to both suppliers and retailers, the important one, is surely the opportunity to open a close collaboration in order to overcome potential issues and enable new opportunities of gaining competitive advantage over other competitors.

Vendor Managed Inventory (VMI) also called Co-Managed Inventory (CMI) is another of "win-win” thinking that emerged in the SC.It is based on a close partnership between buyer and supplier. This method was developed in 1980 and is now used on different business sectors. In the grocery industry, with Vendor Managed Inventory usually comes along another method named continuous replenishment. VMI and CR were firstly adopted by Procter \& Gamble and Wal-Mart in the United States of America. The success of this partnership gave a strong impulse for the promulgation of this technique. CR improves ECR strategy (Cooke, J.A., 1998).In the continuous replenishment technique, instead of sharing only the inventory levels, the customers generate sales forecasts from Point of sale (POS) data and share them with suppliers, giving them visibility to real demand. The high visibility in the SC doesn't only permits gains in the production planning process, but also, solving particular issues at the store level, leading to increased sales. Another method named "Collaborative planning, forecasting and replenishment" emerged in 1995 and had the support of corporates from the general commodity, and apparel industries (Blair, N., 1998).

Collaborative planning, forecasting and replenishment process emerged with the ambition to cover the gaps left by prior business practices (VMI and CR). It makes the producer and the retailer share marketplace information with respect to come up with a customer plan which can considerably minimize inventory, keeping the service levels (Frantz, M., 1999).

In definitive, collaboration is a group of complex techniques, associated with set of skills and attitudes that make it realizable. In the SC, it goes beyond mere integrating information between customers and their suppliers, and includes strategic joint decision making among the collaborators in the aspects of collaborative forecasting, distribution, planning, network design, product design, and partnerships. (Kumar, K., 2001, McLaren, T., Head, M. and Yuan, Y., 2002). 


\subsubsection{Integrated SC Collaboration Enablers and the Barriers to Integrated Supply Chain Collaboration}

In a study conducted by Mentzer, J.T., Foggin, J.H. and Golicic, C.L.,(2000), the respondents described SC as an alliance, as it represents the idea of sharing and working together, with a long term perspective. In a similar way as in a marriage, a collaborative relation only survives with a commitment of both collaborators. Developing a collaborative relationship requires effort; however there are some enablers that can simplify the task. These enablers can be classified into three principal groups: technology, organization, and people.

The principal enablers identified by Mentzer, J.T., Foggin, J.H. and Golicic, C.L.,(2000) are: Trust, Longevity of the relationship, Openness, and Leadership, Technology, and Benefit sharing.

Cooke, J. A., (2003) referred another important enabler to collaboration. According to him most of the corporate today suffers from the "silo" complex. He illustrated his point of view with the following anecdote: "in a typical silo corporate, the workers within each department are rewarded for meeting departmental goals. A logistics manager may receive an annual bonus for keeping logistics costs down, not for leading to a higher overall efficiency. This leaves the manager with absolutely no motivation to collaborate on a project, and will minimize SC costs, but is going to increase his department's expenses. This illustration demonstrates the importance of having in place a measurement system that can capture the benefits of collaboration.

The barriers to the achievement of partner relationships are factors that limit the business collaborator's visibility in the SC. Barratt and Oliveira,(2001) ,and Cooke, J. A. ,(2003) identified the following main barriers :Weak replenishment in response to demand fluctuations; Ineffective planning using visibility of point of sales (POS) customer demand; Incapacity to manage the forecast review processes; Promotions and new products events are not jointly planned; Lack of trust and sharing between business partners; Scalability and getting critical mass; Non existence of an integrated decision support system to provide customer, consumer and market data; Measures are not externally focused; Ongoing change management; Conventional accounting practices; Poor communication between business partners; Betrayal of one of the partners; Annual negotiation process; Time investment.

There are some barriers that are linked to the development of a collaborative relationship and others are associated with maintaining the relationship. This shows that there are probably a set of skills to start to collaborate, followed by an effort to maintain with the expectations of both business partners.

\subsubsection{The Advantages of Collaboration}

Several authors discussed the value of collaborative communication within the Supply Chain but often without making the difference between the process driven and relationship driven communication. While the communications occur simultaneously and in accordance with each other, these two aspects may present a connection, which slow down the analysis of Supply Chain performance. Some authors do not distinguish between these aspects because they see process and relationship as unified factors that describe Supply Chain communications. Some authors choose factors from these aspects deliberately to examine specific aspects of the Supply Chain. Others authors may make the difference and decide to examine other of the aspects.

The aspect of relationships in organization behavior can be used to classify a number of researches.

Min, S., Roath, A.S., Daugherty, P.J., Genchev, S.E., Chen, H. and Arndt, A.D. (2005) proposed a conceptual model of Supply Chain collaboration, which include three elements (Antecedents, Collaboration and Consequences). The antecedents to collaboration were identified as; strategic purposes, relationship-specific investment, internal alignment, relationship orientation, free flow of information and heightened communication and lastly, formalization. The attribute of collaboration was identified by three important constructs; relationship interaction, behaviors, and culture. These revealed the characteristics of; joint planning, shared information, joint performance measurement, joint problem solving, and leveraging resources and skills. The benefits of collaborations, were positive effect specified as; profitability, effectiveness, mutual efficiency, and reinforcement of the relationship.

Cox, A. (1999) demonstrated that operational efficiency is best appreciated in terms of business strategy where the most important factor is the role of power usurper in the Supply Chain relationship. The corporate that haves more power has the capacity to adopt value from the relationships with others, if these are with suppliers, customers, or employees.

Kidd, J., Richter, F.J. and Stumm, M. (2003) promoted the important function of trust in knowledge management and organizational learning in Supply Chain systems. This is especially important with the beginning of globalization. Duffy, R. and Fearne, A. (2004) assert that with the overture of Efficient Consumer Response and its dependency on relationships based on cooperation and trust, mutual benefits for the whole Supply Chain are achieved. Efficient Consumer Response works because of a collaborative sharing of crucial information, risks and rewards. The test for if 
the relationships are cooperative is in the critical predictors, which lie in the constructs of trust, commitment, relational norms and conflict resolution methods. This is approved from a logistics view by Daugherty, P.J., Ellinger, A.E. and Gustin, C.M. (1996) who generated survey results, which promote the incorporation of logistics throughout the channel system with a mention of the benefits where it succeeds.

The overlapping of the aspects, as explained above is demonstrated by.Croxton, K.L., Lambert, D.M and Garcia-Dastugue, S.J. (2005), when they assess the process oriented Supply Chain designs of the Supply Chain Forum and the Supply Chain Council. They quote the Global Supply Chain Forum framework as having eight Supply Chain Management processes: customer service management, customer relationship management, order fulfillment, demand management, manufacturing flow management, supplier relationship management, product development and commercialization and returns management. It is important to note that they comment on process orientation yet quote relationships as important to these processes. While they declare that the aim of Supply Chain Management is to increase the value of a corporate. They recognize that the two aspects are not respectively exclusive because transactional efficiency should be an outcome of good relationship management. Finally, Min, S. and Mentzer, J.T. (2004) accurately tested a theoretical framework based on Supply Chain Orientation and Supply Chain Management. Their framework brings a similarity to our two dimensions of process and relationships where Supply Chain Management is similar to the earlier and Supply Chain Orientation to the latter. They define Supply Chain Orientation as the systemic, strategic implications of tactical activities to relational factors such as trust and commitment to Supply Chain Relationship and Supply Chain Management as the management of traditional business functions within the business and across the Supply Chain to ameliorate long-term performance of the individual corporate and the whole Supply Chain. A pool of twenty scale items for Supply Chain Orientation and thirty items for Supply Chain Management used in the test were statistically significant and the results generated a positive, significant regression coefficient for business performance.

Reliable relationships can be an advantage because the time spent on activities of both groups can be optimized by minimizing credential checking, prequalification and process auditing, while accessing the combined resources of both groups to allow a division of tasks. Kanter, R.M. (1994) found the eight I “s” of collaborative advantage in such relationships with an accent on the incorporation of these by mutual trust. On the other side, the disadvantage of this nearness is a restriction on corporate autonomy, resources to maintain the relationship and manage current processes, and the real possibility of future deficit to the other. There is also the termination cost of the relationship should it be uncontrollable.

The relationships between corporate that interconnect to form networks however, show common features, summarized as:

-Mutuality/Reciprocity (every business partner is supposed to provide some balanced share to the specific transactions).

-Loose coupling (stable design for interaction and communication).

- Boundaries of responsibility (individual boundaries partners activities and responsibilities).

- Power (inherent power relationships usually having an organizing partner).

These features emphasize the necessity for communication and collaboration in the relationship with a commitment to trust, shared values and aligned objectives.

The mechanism model, which symbolizes technical and operational relationships, is described in the operational indicators of the performance pyramid scheme. The main idea of this study is that the efficient operation of the whole Supply Chain depends on the effective operation of communication channels that are required by these interactions as they are manifested in the relationships.

It is the relationships promoted by collaboration and trust that integrate the Supply Chain and provides the competitive advantage in business operations. It is the rationales of this study therefore, that collaboration and trust as subsets of the organizational behavior in the Supply Chain network are contributors to Supply Chain performance and authenticate measurement. As the Supply Chain Network is a conglomeration of "B2B" interactions, essentially between two business partners, it is the contributions of these couples that must be measured and compared. The researchers believe that this approach of measuring Supply Chain performance is new and provides a contribution to the study of Supply Chain Management. A new application of the non-parametric method may provide appropriate method to measure performance in Supply Chain. 


\section{Data Envelopment Analysis (DEA)}

Data envelopment analysis (DEA) is a non-parametric method in operations research and economics generally used to evaluate the relative performance of a set of units that are identical. The units are named decision-making units (DMUs) and their alikeness lies in their pattern of input and output processes. Data Envelopment Analysis combines important performance ratio outputs and inputs into a single number that denotes productivity (efficiency). DEA uses analytical programming to analyze the observed outputs and inputs for the units under research, it determines the comparatively best practice units to define an effective boundary, and it evaluates the degree of incompetence of the other units relative to this boundary.

The original Data envelopment analysis model of Charnes, A., Cooper, W.W. and Rhodes, F. (1978), designate as the Charnes Cooper Rhodes ratio form ( Cooper, W.W., Seiford, L.M. and Tone, K.,2000) was based on their extension of Farrell, M.J.,(1957) technical efficiency measure of performance expressed as a ratio of a single input and a single output.

Sexton, T., (1986) has described Data Envelopment Analysis in terms of a set of linear programming models as follows:

For $k=1,2,3, \ldots, k$

Subject to:

$$
\operatorname{Max} E_{k}=\sum_{j=1} x_{f k} y_{f k}
$$

$$
\begin{aligned}
& \sum w_{1} w_{j k} y_{m}-\sum \sum_{1} v_{l k} x_{m} \leq 0 \text { for all } n=1,2 \ldots N \\
& \sum \sum_{-1} v_{m} x_{m}=1
\end{aligned}
$$$$
u_{j h}, v_{i k} \geq 0
$$

Where $\varepsilon_{j / \hbar}$ and $v_{i \bar{k}}$ are the comparative weights joined to output $J$ and input $I$ in the model for $k$ th DMU.

$\boldsymbol{E}_{\boldsymbol{k}}$ represent the efficiency of the $k$ th DMU,

$y_{j n}$ represent the assessed units of output $l=1,2, \ldots, m$ for the $n$th DMU.

$x_{\text {in }}$ represent the assessed units of input $t=1,2 \ldots, r$ for the $n$ thDMU

The $\mathrm{N}$ coercions in each of the $\mathrm{N}$ linear programs confirm that no DMU can accomplish an effective rating which will surpass unity. The optimization produces a positive set of $u_{j k}^{*}$ and $v_{k}^{*}$ which produce a maximum

$0 \leq E_{R}^{s} \leq 1$ with $E_{k}^{s}=1$ if, and only if(iff), $D M U-k$ is efficient.

In other words, Data envelopment analysis (DEA) determines the efficiency of an arbitrary unit $i$ as:

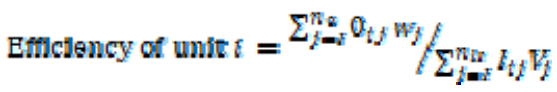

Oij corresponds to the unit value $i$ on output $j$; Iij corresponds to the unit value $i$ on input $j$; $w$ is the non negative weight assigned to output $j ; v$ is the non negative weight assigned to input $i ; n$ is the number of output and input variables.

Different from the parametric approaches, which necessitate a specific operational form expressing relationships between dependent and independent variables, Data envelopment analysis estimates the highest performance of each Decision Making Unit in relation to other Decision Making Unit in the population. It does this by providing an external frontier which describes the optimum performance perimeter where proportionately efficient Decision Making Units occupy, manages at various points of the effectiveness line.

The relative technical efficiency (Cooper, W.W., Seiford, L.M. and Tone, K.,2000) of each Decision Making Unit is expressed as a percentage matched against the best Decision Making Units, which shows the best practice production frontier, the maximum output empirically obtainable with a given amount of input. Enhancement for the lower performing units is possible by different manipulations of the productivity ratio, such as keep increasing the output while stabilizing input, decreasing input for an unchanged output or a range of options (Charnes, A., Cooper, W.W., Lewin, A.Y. and Seiford, L.M.,1994) basing on the adapted improvement strategy for current economic conditions.

Data envelopment analysis has a great attraction to researchers because of three factors:

-each Decision Making Unit has a unique score to indicate efficiency

-possible improvement for each Decision Making Unit is benchmarked against the best-practice referent Decision Making Unit and

-Decision Making Unit restrains the need for alternate abstract inferential statistical models. 
Moreover, a limited number of recent researches have demonstrated new use of Data envelopment analysis in areas of increasing academic interest, such as the relation between the policies of proactive environmental and corporate performance ( Sarkis, J. and Cordeiro, J.J.,2001) and effect of corporate social responsibility on organizational performance, Data envelopment analysis is also progressively used in conjunction with other methods, such as Analytic Hierarchy Process (AHP) and utilized to measure qualitative data as a beginning to further analysis ( Zhu, 2003;Sarkis, J.,1999).

Contrary to other descriptive and inferential calculations Data envelopment analysis focuses on individual observations as single efficiency measures rather than population averages. Various input and output measures using different units can be adapted, as can the inclusion of dummy variables, and while these factors are treated as value free they can be weighted to include base on knowledge from the judgments of experienced managers. To conclude, Data envelopment focuses on benchmarking against existing best practice rather than on central tendency measure.

\section{.3.1 DEA Application in a Supply Chain Network Framework}

An example chosen for illustrative intentions is presented in Table 1, where the Decision Making Units are inherent entities representing Supply Chain "relationships dyads". The Data envelopment analysis can be applied to intra-corporate and inter-corporate Supply Chain Decision Making Units as a vertically integrated manufacturing corporate with several manufactories, supplier and distributor subsidiaries, all under corporate control, as well as the horizontal Supply Chain of the external partners. For this paper we identify the logistics relationships.

For example, one Decision Making Unit can be the inherent entity depicted by the relationship between the Core corporate and a supplier, while another can be the entity of the relationship between Core corporate and a distributor.

Similarly other Decision Making Units may be the virtual entities created between the relationships of different suppliers and distributors in the horizontal and vertical Supply Chain Networks that exist. The different Supply Chain Relationship that may exist could be those between the IC and "category 1" suppliers, between IC and "category 2" suppliers and between IC and the major distributors. Additional dyad that exists between chain partners and inclusion of warrants for benchmarking relationships can be added to the Decision Making Units computations. The details are presented in Figure 2. Every RDs eventually become independently determined Decision Making Units in the Data envelopment analysis algorithm.

Table 1 presents the RDs of intra-corporates and inter-corporates relationships in the Supply Chain, with sample identifiers marked with index “e "(External), “I”(Internal), "s”(Supplier) and “ $d$ ” (Distributor). "Bis” represents the "virtual" link between an internal supplier with the Common Flows while Ged is the Decision Making Unit for extern distribution relationship and Les is that for an external supplier. Corresponding input factors for all Decision Making Units could be rated responses on computerized questionnaires for; strategic alignment, information sharing, relationship commitment and communication Flows . Corresponding outputs could be; point planning, joint KPIs , responsiveness and formalization. These outputs factors have been chosen as examples of the variables that could be used in Data envelopment analysis and they come from researches such as Min, S. and Mentzer, J.T. (2004).

The results computation (Cooper, W.W., Seiford, L.M. and Tone, K., 2000; Ragsdale, C.T.,2004; Zhu, 2003) indicate that Decision Making Units B, G and L are equitably efficient Supply Chain relationship members with a score of 1.00 (100\%) where intra and inter-corporate partners could all be treated as equitably discrete and comparable so long as the inputs and outputs are identical variables in the Supply Chain Network.

\section{Findings and implications}

The previous illustrations shows that the corporate supervisors in nonperforming DMUs ( RDs with less than 1.00 rating) have an important challenge that need to be ameliorated ( there are relationships in the Supply Chain Network(SCN) that are performing better in terms of collaboration and trust than others). The major implication of these can be recapitulated as following: the underperforming RDs have measures of their own under-achievement enumerated. An investigation of the input and output factors against the same factors of the best performers can provide managers with good strategies that should concrete the way forward. This provides a good opportunity for individual RD improvements with the result that the Supply Chain improves. Addressing the factors that necessitate attention should not be excessively difficult since the benchmark performers show their component factor scores. The limitation of the design presented in this study is that it is explanatory and based on work that has been investigated elsewhere. Some of the difficulties in the methodological problems of that work would be expected here: the choice of the Decision Making Units and the exact input and output factors would be important to the measurement outcome and to the effectiveness of Data envelopment analysis's ability to discriminate efficient from non-efficient Decision Making Units. 


\section{Conclusion and future directions}

As the result of this study, a method for assessing the extent of supply chain collaboration has been provided and the impacts of collaborative practices on functional performance have been investigated. The concept of supply chain collaboration was characterized into three elements, namely Antecedents, Collaboration and Consequences. The antecedents to collaboration were recognized as strategic purposes, relationship-specific investment, internal alignment, and relationship orientation, free flow of information and heightened communication and lastly, formalization. The attribute of collaboration was identified by three important constructs; relationship interaction, behaviors, and culture. These revealed the characteristics of joint planning, shared information, joint performance measurement, joint problem solving, and leveraging resources and skills. The benefits of collaborations, were positive effect specified as; profitability, effectiveness, mutual efficiency, and reinforcement of the relationship.

An example, based on case study was chosen for illustrative intentions is where the Decision Making Units are inherent entities representing Supply Chain "relationships dyads". The Data envelopment analysis was applied to intra-corporate and inter-corporate Supply Chain Decision Making Units with many manufactories, suppliers and distributor subsidiaries, all under corporate control, as well as the horizontal Supply Chain of the external partners.

The result of this case study shows that the managers in non-performing Decision Making Units have a great challenge that need to be improved: there are relationships in the Supply Chain Network that are performing better in terms of collaboration and trust than others.

Finally Data envelopment analysis has introduced a good instrument for the assessment of performance in the supply chain. Its processing is reliably conclusive in its interpretation once the correct parameters have been demonstrated. Although first trials in a current examination are encouraging, it has not yet been tested on all the performance metrics in the pyramid, including the Supply Chain Network. This new challenge is to determine and apply those input/output factors for each pyramid dimension that will provide the efficiency computation for a performance scorecard (PSC). The study provides a new direction for further research in term of investigating the importance of this method in organizational contexts across a variety of commercial corporate in the Gabonese economy.

\section{References}

Arndt, R. Glenn Richey, (2005).Supply chain collaboration: what's happening?, International Journal of Logistics Management, The, Vol. 16 Iss: 2, pp.237 - 256

ATMAE Membership Venn Diagram. http://atmae.org/index.php?option=com_content\&view=article\&id=227\&Itemid=48

Axelroad, R.,(1990). The evolution of co-operation. Penguin Books, Harmondsworth, 1990

Barratt, M. and Oliveira, A. (2001), “Exploring the experiences of collaborative planning initiatives”, International Journal of Physical Distribution \& Logistics Management, Vol. 31No. 4, pp. 266-89.

Beamon, B.M. (1998) .Supply chain design and analysis: models and methods, International Journal of Production Economics, Vol. 55, No. 3, pp.281-294. doi:10.1016/S0925-5273(98)00079-6, http://dx.doi.org/10.1016/S0925-5273(98)00079-6

Berg, S. (2010). Water Utility Benchmarking: Measurement, Methodology, and Performance Incentives.International Water Association.

Blair, N., (1998).Minding the store: with inventory reduction measures under way in the warehouse, executives are eyeing similar strategies based on store-level data. Supermarket News, Vol. 48, No. 3, pp. 81-2, 1998

Bowersox, D.J. (1990), “The strategic benefits of logistics alliances”, Harvard Business Review,Vol. 68 No. 4, pp. 36-43.

Bowersox, D.J., Closs, D.J. and Keller, S.B. (2000), “How supply chain competency leads to business success”, Supply Chain Management Review, Vol. 4 No. 4, pp. 70-8.

Chan, F.T.S. and Qi, H.J. (2003) .An innovative performance measurement method for supply chain management, Supply Chain Management: An International Journal, Vol. 8, No. 3,pp.209-223.

Charnes, A., Cooper, W.W. and Rhodes, F. (1978) .Measuring the efficiency of decision making units, European Journal of Operational Research, Vol. 2, pp.429-444. doi:10.1016/0377-2217(78)90138-8, http://dx.doi.org/10.1016/0377-2217(78)90138-8 
Charnes, A., Cooper, W.W., Lewin, A.Y. and Seiford, L.M. (1994) Data Envelopment Analysis: Theory, Methodology, and Application, Boston: Kluwer Academic Publishers.

Cooke, J. A. ,(2003).Want real collaboration? Change your measures. Logistics Management, Vol. 42, No. 1, pp. 37-41, 2003

Cooke,J.A.,(1998) .VMI: very mixed impact?. Logistics Management Distribution Report, Vol.37, No. 12, p. 51, 1998

Cooper, W.W., Seiford, L.M. and Tone, K. (2000) Data Envelopment Analysis: A Comprehensive Text with Models, Application, References and DEA Solver Software, Massachusetts: Kluwer Academic Publishers.

Corbett, C.J., Blackburn, J.D. and Van Wassenhove, L.N. (1999), “Partnerships to improve supply chains”, Sloan Management Review, Vol. 40 No. 4, pp. 71-82.

Cox, A. (1999) .Power, value and supply chain management, Supply Chain Management: An International Journal, Vol. 4, No. 4, pp.167-175.

Daugherty, P.J., Ellinger, A.E. and Gustin, C.M. (1996) .Intergrated logistics: achieving logistics performance improvements., Supply Chain Management, Vol. 1, No. 3, pp.25-33. doi:10.1108/13598549610155297, http://dx.doi.org/10.1108/13598549610155297

Dell, M. and Fredman, C. (1999), Direct from Dell, HarperCollins Business, London.

Dillman, D.A. (1978), Mail and Telephone Surveys: The Total Design Method, Wiley, New York,NY.

Duffy, R. and Fearne, A. (2004).The impact of supply chain partnerships on supplier performance, The International Journal of Logistics Management, Vol. 15, No. 1, pp.57-71. doi:10.1108/09574090410700239, http://dx.doi.org/10.1108/09574090410700239

ECR Europe (1997). A Newsletter for European Retailers, Suppliers and Distributors.

Farrell, M.J. (1957) .The measurement of productive efficiency, Journal of the Royal Statistical Society, Vol. 120, pp.254-290. doi:10.2307/2343100, http://dx.doi.org/10.2307/2343100

Fisher, M.L. (1997), "What is the right supply chain for your product?”, Harvard Business Review,Vol. 75 No. 2, pp. 105-16.

Frantz, M.,(1999). CPFR pace picks up. Consumer Goods, January, 1999

Ivan Turok (2001).Area-based partnerships in Ireland: collaborative planning in practice. Paper for EURA conference, Copenhagen, May 2001

Judith Montgomery, (2008).The project pyramid .A model for understanding and assessing projects and project capability. From http://ideainterpreter.com/index_files/Idea\%20Products\%20(Free)/The\%20Project\%20Pyramid.pdf

Kanter, R.M. (1994) 'Collaborative advantage: the art of alliances’, Harvard Business Review, July-August, pp.96-108.

Kaplan R S and Norton D P (1992) .The balanced scorecard: measures that drive performance", Harvard Business Review Jan - Feb pp. 71-80.

Kaplan, R.S. and D.P.Norton (1996) .Using the balanced scorecard as a strategic management system, Harvard Business Review, January-February, pp.75-86.

Kaplan,R.S. and D.P.Norton, (1993) .Putting the Balanced Scorecard to Work, Harvard Business Review Sep - Oct pp2-16.

Kidd, J., Richter, F.J. and Stumm, M. (2003). Learning and trust in supply chain management: disintermediation, ethics and cultural pressures in brief dynamic alliances, International Journal of Logistics, Vol. 6, No. 4, pp.259-275. doi:10.1080/13675560310001626972, http://dx.doi.org/10.1080/13675560310001626972

Kumar, K.,(2001).Technologies for supporting supply chain management. Communications of the ACM, Vol. 44, No. 6, pp. 58-61, 2001, doi:10.1145/376134.376165, http://dx.doi.org/10.1145/376134.376165

Kurt Salmon Associates (1993).Efficient Consumer Response: Enhancing Consumer Value in the Grocery Industry.

Lambert, D.M. and Pohlen, T.L. (2001), “Supply chain metrics”, International Journal of Logistics Management, Vol. 12 No. 1, pp. 1-19. doi:10.1108/09574090110806190, http://dx.doi.org/10.1108/09574090110806190 
Lambert, D.M., Garcia-Dastugue, S.J. and Croxton, K.L. (2005) .An evaluation of process-oriented supply chain management frameworks, Journal of Business Logistics, Vol. 26, No. 1, pp.25-51. doi:10.1002/j.2158-1592.2005.tb00193.x, http://dx.doi.org/10.1002/j.2158-1592.2005.tb00193.x

Li, Z., Kumar, A. and Lim, Y.G. (2002) .Supply chain modelling- a co-ordination approach, Integrated Manufacturing Systems, Vol. 13, No. 8, pp.551-561. doi:10.1108/09576060210448134, http://dx.doi.org/10.1108/09576060210448134

Lofton, Lynn,(2006). Technology's impact on business communication unabated. The Mississippi Business Journal

MacLaren,T., Head M.,Yuan Y.,(2002),“Supply chain collaboration alternatives:understanding the expected costs and benefits ,Internet Research: Electronic Networking Applications and Policy,Vol.12,No.4,pp348-364, doi:10.1108/10662240210438416, http://dx.doi.org/10.1108/10662240210438416

Marianne Kinnula(2004).An Outsourcing Partnership Model FRONTIERS OF E-BUSINESS RESEARCH 2004.

Maurice Atkinson (2005). The Development of an Evaluation Framework for Partnership Working. Electronic Journal of Business Research Methods Volume 3 Issue 12005 (1-10)

McLaren, T., Head, M. and Yuan, Y.(2002). Supply Chain Collaboration alternatives:understanding the expected costs and benefits. Internet Research: Electronic Networking Applications and Policy, Vol. 12, No. 4, pp. 348-364, 2002, doi:10.1108/10662240210438416, http://dx.doi.org/10.1108/10662240210438416

Mentzer, J.M., Min, S. and Zacharia, Z.G. (2000), “The nature of interfirm partnering in supply chain management”, Journal of Retailing, Vol. 76 No. 4, pp. 549-68. doi:10.1016/S0022-4359(00)00040-3, http://dx.doi.org/10.1016/S0022-4359(00)00040-3

Mentzer, J.T., Foggin, J.H. and Golicic, C.L,( 2000). Collaboration: the enablers, impediments, and benefits. Supply Chain Management Review, September/October, 2000

Min, S. and Mentzer, J.T. (2004) .Developing and measuring supply chain management concepts, Journal of Business Logistics, Vol. 25, No. 1, p.63. doi:10.1002/j.2158-1592.2004.tb00170.x, http://dx.doi.org/10.1002/j.2158-1592.2004.tb00170.x

Min, S., Roath, A.S., Daugherty, P.J., Genchev, S.E., Chen, H. and Arndt, A.D. (2005) .Supply chain collaboration: what's happening?The International Journal of Logistics Management,Vol. 16, No. 2, pp.237-256. doi:10.1108/09574090510634539, http://dx.doi.org/10.1108/09574090510634539

Narus, J.A. and Anderson, J.C. (1996), “Rethinking distribution: adaptive channels”, Harvard Business Review, Vol. 74 No. 4, pp. 112-20.

Norreklit H. (2000), The balance on the balanced scorecard - a critical analysis of some of its assumptions, Management Accounting Research, 11, pp. 65-88. doi:10.1006/mare.1999.0121, http://dx.doi.org/10.1006/mare.1999.0121

Poirier, C.C. (1999), Advanced Supply Chain Management, Berrett-Koehler, San Francisco, CA.

Polese, W.T. (2002), "Measuring the success of collaboration across the virtual supply chain through performance measurement systems and benchmarking”, Supply Chain World Conference and Exposition, New Orleans, LA, April 23.

Ragsdale, C.T. (2004) Spreadsheet Modelling and Decision Analysis, 4th edition, Mason,OH: Thomson South-Western.

Ramdas, K. and Spekman, R.E. (2000), “Chain or shackles? Understanding what drives supply-chain performance”, Interfaces, Vol. 30 No. 4, pp. 3-21. doi:10.1287/inte.30.4.3.11644, http://dx.doi.org/10.1287/inte.30.4.3.11644

Robins.G.,(1994) Sailing into ECR’s uncharted waters. Stores, Vol. 76, No. 10, pp. 43-4, 1994

Ron Das(2009).Supply Chain Innovation: Responding to Dynamic Challenges. Vol.16 No.3 Sept. 2009. GSA(U.S.)

Sarah Shaw, David B. Grant, John Mangan, (2010) "Developing environmental supply chain performance measures", Benchmarking: An International Journal, Vol. 17 Iss: 3, pp.320 - 339 10.1108/14635771011049326

Sarkis, J. (1999) .A methodological framework for evaluating environmentally conscious manufacturing programs, Computers and Industrial Engineering, Vol. 36, No. 4, pp.793-810. doi: 10.1111/j.1540-5915.1999.tb01609.x, http://dx.doi.org/10.1111/j.1540-5915.1999.tb01609.x 
Sarkis, J. and Cordeiro, J.J. (2001) .An empirical evaluation of environmental efficiencies and firm performance: pollution prevention versus end-of-pipe practice, European Journal of Operational Research, Vol. 135, No. 1, pp.102-113. doi:10.1016/S0377-2217(00)00306-4, http://dx.doi.org/10.1016/S0377-2217(00)00306-4

Sexton, T., (1986), “The Methodology of Data Envelopment Analysis” in Richard H. Silkman editor, Measuring Efficiency: An Assessment of Data Envelopment Analysis, Jossey-Bass, San Francisco.

Simatupang, T.M. and Sridharan, R. (2002), “The collaborative supply chain”, International Journal of Logistics Management, Vol. 13 No. 1, pp. 15-30. doi:10.1108/09574090210806333, http://dx.doi.org/10.1108/09574090210806333

Simatupang, T.M. and Sridharan, R. (2004), “A benchmarking scheme for supply chain collaboration”, Benchmarking: An International Journal, Vol. 11 No. 1, pp. 9-30. Doi: 10.1108/14635770410557717, http://dx.doi.org/10.1108/14635770410557717

Soonhong Min, Anthony S. Roath, Patricia J. Daugherty, Stefan E. Genchev, Haozhe Chen, Aaron D. Arndt, R. Glenn Richey, (2005) "Supply chain collaboration: what's happening?", International Journal of Logistics Management, The, Vol. 16 Iss: 2, pp.237 - 256, doi:10.1108/09574090510634539, http://dx.doi.org/10.1108/09574090510634539

STEVENS, G.C. (1989). Integrating the supply chain. International Journal of Physical Distribution and Materials Management, Vol. 19, No. 8, 1989.

Stewart, G. (1997), "Supply-chain operations reference model (SCOR): the first cross-industry framework for integrated supply chain management”, Logistics Information Management, Vol. 10 No. 2, pp. 62-7. doi:10.1108/09576059710815716, http://dx.doi.org/10.1108/09576059710815716

Sumanth, D.J. (1984) Productivity Engineering and Management, New York: McGraw-Hill Book Company.

Tan, K.C., V.R. Kannan and R.B. Handfield. (1998)"Supply Chain Management: supplier Performance and Firm Performance," International Journal of Purchasing and Materials Management, (34:3), 1998, pp. 2-9.

U.S. Department of Education Institute of Education Sciences: Classification of Instructional Programs (CIP). Retrieved on October 26, 2009 fromhttp://nces.ed.gov/pubs2002/cip2000/occupationallookup6d.ASP?CIP=52.0205

Zhu, J. (2003). Quantitative Models for Performance Evaluation and Benchmarking, Boston: Kluwer Academic Publishers. doi:10.1002/ejoc.200390167

Table 1. Efficiency estimation of RDs, and input, output

\begin{tabular}{|lcccccccccccc|}
\hline DMUs (RDs) & A & Bis & C & D & E & F & Ged & H & I & J & K & Lec \\
\hline Strategic Alignment (SA) & 4.76 & 6.41 & 5.06 & 3.60 & 3.46 & 5.26 & 2.37 & 7.08 & 6.50 & 7.37 & 5.46 & 6.59 \\
Information Sharing (IS) & 6.76 & 7.43 & 6.37 & 6.36 & 4.44 & 6.40 & 3.24 & 8.70 & 7.27 & 9.08 & 6.70 & 8.76 \\
Relationship commitment (RC) & 5.88 & 7.19 & 4.98 & 5.33 & 3.40 & 4.96 & 2.90 & 6.41 & 6.02 & 6.95 & 5.86 & 8.35 \\
Common Flows (CF) & 7.90 & 9.80 & 9.50 & 7.80 & 7.90 & 7.80 & 8.70 & 9.20 & 7.40 & 8.90 & 8.21 & 9.70 \\
Joint Planning (JP \%) & 91.00 & 98.00 & 99.00 & 88.00 & 94.00 & 89.00 & 91.00 & 100.00 & 89.00 & 90.00 & 93.00 & 97.00 \\
Joint KPIs (JKPI) & 59.00 & 77.00 & 57.00 & 72.00 & 55.00 & 46.00 & 92.00 & 77.00 & 32.00 & 57.00 & 92.00 & 95.00 \\
Responsiveness(R) & 78.00 & 87.00 & 47.00 & 62.00 & 60.00 & 92.00 & 94.00 & 72.00 & 51.00 & 51.00 & 59.00 & 89.00 \\
Formalisation (F) & 82.00 & 88.00 & 78.00 & 44.00 & 76.00 & 59.00 & 72.00 & 88.00 & 69.00 & 58.00 & 78.00 & 84.00 \\
Efficiency & 0.97 & 1.00 & 0.84 & 1.00 & 8.84 & 0.83 & 1.00 & 0.76 & 8.85 & 0.79 & 0.91 & 1.00 \\
\hline
\end{tabular}




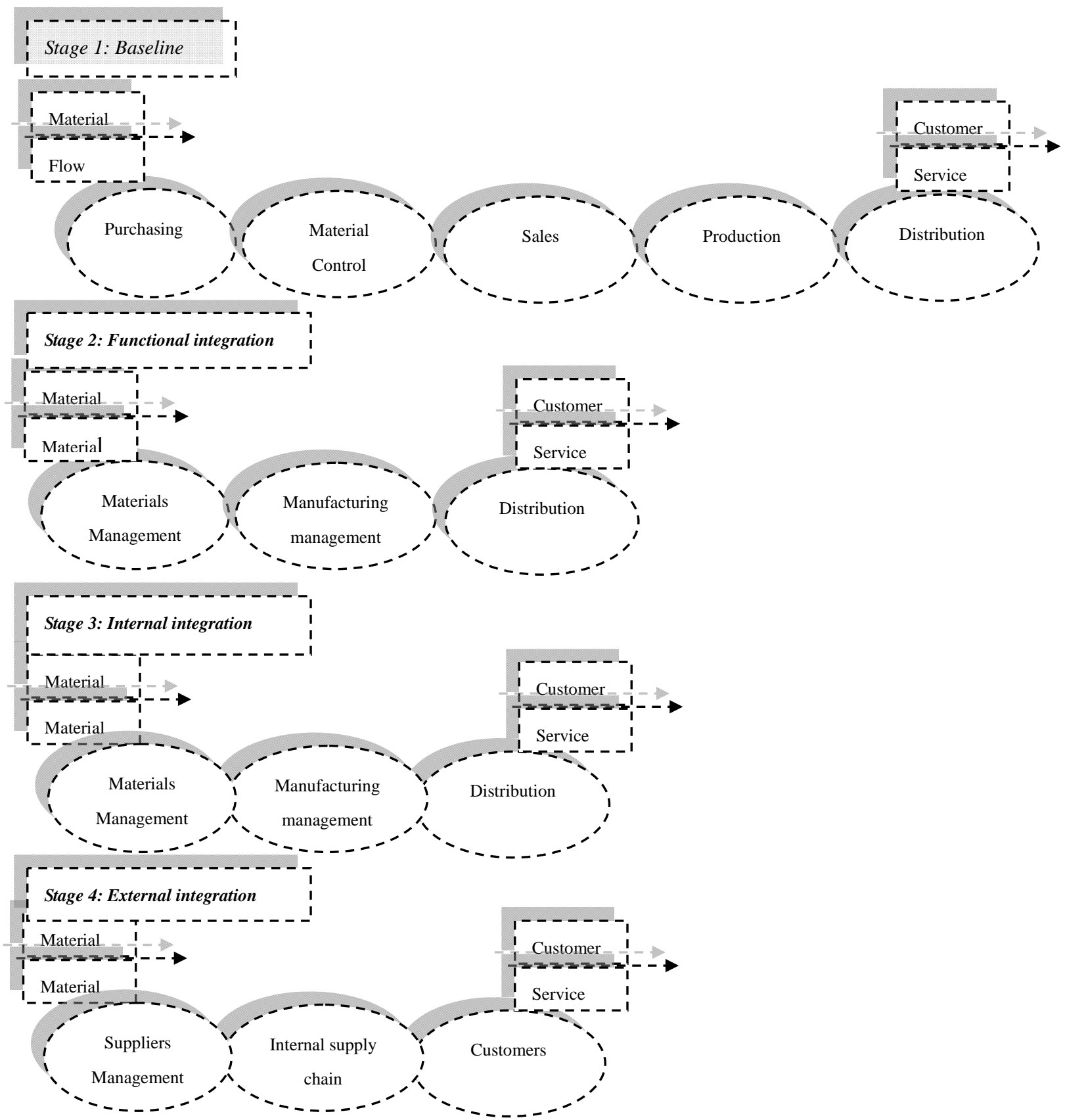

Figure 1. Achieving an integrated supply chain 


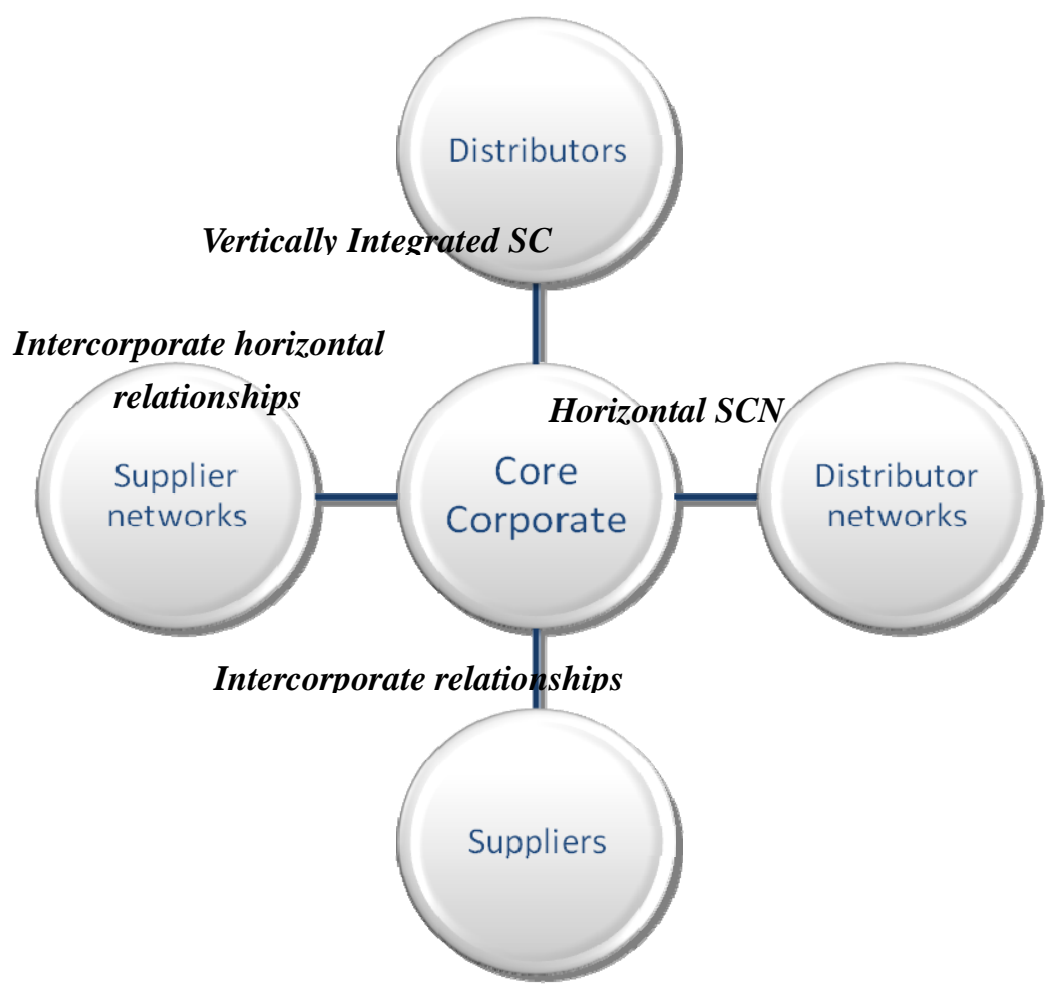

Figure 2. Relationship outputs and inputs for virtual Decision Making Units 